\title{
The effect of semantic ambiguity on reading aloud: A twist in the tale
}

\author{
JENNIFER M. RODD \\ University of Cambridge, Cambridge, England
}

\begin{abstract}
Despite numerous studies investigating whether semantic representations are involved in the process of reading aloud, the issue remains controversial. While some studies report significant effects of semantic variables on this task (e.g., Fera, Joordens, Balota, Ferraro, \& Besner, 1992; Strain, Patterson, \& Seidenberg, 1995), other studies have highlighted possible problems with these studies (e.g., Borowsky \& Masson, 1996; Monaghan \& Ellis, 2002). The experiments reported here use semantic ambiguity as a marker for semantic involvement and confirm that semantic representations can indeed affect reading aloud, but that the size of semantic effects is influenced by the consistency of the words and the speed with which participants respond.
\end{abstract}

Current theories of reading aloud make different claims about the role of semantics. The dual-route theory of reading proposes two main routes for reading: The nonlexical route computes pronunciations on the basis of rules about how individual graphemes are pronounced, while the lexical route produces words' pronunciation by activating their lexical entries. However, in addition to these two routes, there is a semantic subroute within the lexical route. Current computational models that instantiate this theory (e.g., Coltheart, Rastle, Perry, Ziegler, \& Langdon, 2001) have not implemented this semantic subroute and make no strong claims about when it plays a role. The influence of the semantic route may be minimal for reading single words in isolation, and therefore this theory is consistent with results showing that semantic representations are not involved in reading single words aloud. However, if this semantic route is involved in reading single words, its impact is likely to be largest for words with irregular spelling (e.g., pint); the output from the nonlexical route is incorrect for these words, and the model relies on the lexical route (and its semantic subroute) to produce the correct output.

An alternative to the dual-route account of reading aloud was proposed by Seidenberg and McClelland (1989). They argued that a single route can pronounce both regular and irregular words. However, in addition to this single route there is a semantic route. In a later version of this model (Plaut, McClelland, Seidenberg, \& Patterson, 1996), the authors argued that the semantic route is critical for reading low-frequency irregular words (for which the mapping between print and pronunciation is particu-

This work was supported by a Research Fellowship from Peterhouse, Cambridge, to J.R. and an MRC program grant to L. K. Tyler. Correspondence should be addressed to J. Rodd, Centre for Speech and Language, Department of Psychology, University College London, 26 Bedford Way, London WC1 0AP, England (e-mail: jrodd@ucl.ac.uk). larly difficult). Therefore, this model predicts that any effects of semantic variables should be largest for lowfrequency irregular words.

This prediction was supported by Strain, Patterson, and Seidenberg (1995), who reported slower and less accurate reading for irregular words with abstract meanings (e.g., scarce) than for imageable irregular words (e.g., soot). There was no imageability effect for words that were high frequency or regular. This imageability $\times$ regularity interaction was replicated by Strain and Herdman (1999) and Strain, Patterson, and Seidenberg (2002). However, Monaghan and Ellis (2002) and Ellis and Monaghan (2002) have questioned these results, suggesting that age of acquisition (a nonsemantic variable) may cause the effect. In the light of this controversy, the study reported here attempts to replicate this interaction with regularity for a different semantic variable - semantic ambiguity.

Several studies have looked for ambiguity effects in naming, with inconsistent results. Some studies have reported an ambiguity advantage (Fera, Joordens, Balota, Ferraro, \& Besner, 1992; Hino \& Lupker, 1996; Lichacz, Herdman, Lefevre, \& Baird, 1999), but others have reported no effect of ambiguity (Borowsky \& Masson, 1996; Chumbley \& Balota, 1984). Although some authors have suggested that this inconsistency reflects the failure of some studies to appropriately control for important variables (e.g., Borowsky \& Masson's, 1996, discussion of Fera et al., 1992), this issue is not fully resolved.

However, unlike the studies of imageability, most ambiguity studies do not consider the words' regularity. Since irregular words (e.g., pint) are read more slowly than regular words (see Coltheart et al., 2001), failure to control stimuli for regularity may produce misleading results. This is particularly important in regard to ambiguity. Ambiguity occurs when a word form refers to multiple concepts. For example, port refers to either a harbor or fortified wine: The first meaning derives from the Latin portus 
and the second meaning from the Portuguese city Opporto (Lyons, 1977). These historical accidents may be more frequent for regular words; it seems unlikely that irregular words like yacht would develop twice independently.

This hypothesis that ambiguous words might (on average) be more regular than unambiguous words is supported by a positive correlation between ambiguity and regularity reported by Borowsky and Masson (1996). Additional support comes from an analysis of the regularity of 2,820 monomorphemic monosyllables (taken from Spieler \& Balota, 1997). Words with more than one entry in the Wordsmyth dictionary (Parks, Ray, \& Bland, 1998 ) were classified as ambiguous. To obtain a measure of regularity, each word's pronunciation was compared with that of other words with the same body. Words with the same body pronunciation are "friends," and words with different pronunciation are "enemies"; for example, beat has both friends (neat) and enemies (great). Words with more friends than enemies were classified as "consistent," and words with more enemies than friends were classified as "inconsistent."' Interestingly, very few of the ambiguous monosyllabic words (7.5\%) are inconsistent, whereas a higher proportion of the unambiguous words are inconsistent (18.3\%). An analysis of the stimuli used by Hino and Lupker (1996) shows that this tendency for ambiguous words to be regular may have affected previous results. For their low-frequency words (which showed the ambiguity effect), a lower proportion of the ambiguous words were irregular (13.3\%: pupil, bowl) compared with the unambiguous words $(32.3 \%$ : evade, veto, wool, deaf, sewer). Since regular words are read more quickly than irregular words, the ambiguity advantage may have been overestimated. An analysis of the response times for this experiment showed that when the irregular words were removed, the ambiguity advantage for the low-frequency words was reduced to $13.5 \mathrm{msec}$, which was not significant $[t(21)=1.4, p=.17]$. Interestingly, Borowsky and Masson (1996) found no ambiguity effect using stimuli that were controlled for regularity. It is therefore important to replicate the ambiguity effect in naming while controlling for regularity/consistency. Furthermore, since both dual- and single-route models predict that any effects of semantic variables should be greatest for inconsistent words, it is important to test whether ambiguity interacts with consistency.

\section{EXPERIMENT 1 Word Naming for Consistent and Inconsistent Words}

This experiment investigated the effect of ambiguity on reading words that have either consistent or inconsistent spelling. Using consistency rather than regularity (the two variables are highly correlated) has two advantages. First, defining regularity requires assumptions about what constitutes regular spelling, whereas consistency is an objective measure. Second, Cortese and Simpson (2000) have shown that the influence of consistency on word-naming latencies is stronger than that of regularity.
The ambiguous stimuli were chosen with respect to the distinction between the accidental ambiguity of words like bark, which have two unrelated meanings, and the systematic ambiguity of words with multiple related senses (e.g., twist). Rodd, Gaskell, and Marslen-Wilson (2002) reported that in lexical decision experiments, while multiple related word senses produce a processing advantage, multiple unrelated meanings delay recognition. They argued that this reflects the differently structured semantic representations of these two kinds of words. The following experiments focused on ambiguity between multiple senses because this form of ambiguity is more common, and this makes it possible to construct well-matched stimulus sets in which consistency is manipulated. ${ }^{2}$ Similarly, although ambiguity effects are likely to be largest in low-frequency words, it was necessary to use mixedfrequency words to ensure good stimulus matching.

\section{Method}

Participants. The participants were 22 University of Cambridge students who were paid for their time and had English as their first language and normal or corrected-to-normal vision.

Stimuli and Design. The stimuli conformed to a factorial design, where the two factors were ambiguity (many vs. few senses) and consistency (consistent vs. inconsistent) (Table 1 and the Appendix). Words with fewer than six senses in the Wordsmyth dictionary (Parks et al., 1998) were classified as having few senses, and those with more than eight senses were classified as having many senses. The four groups of 33 monosyllables were exactly matched for initial consonant cluster (shown to be important by Rastle and Davis, 2002), and were matched for letter length, number of phonemes, log-transformed lemma frequency (natural log of frequency per million, taken from the Celex Lexical Database), concreteness, familiarity, and age of acquisition. Concreteness, familiarity, and age-of-acquisition ratings were obtained from groups of 17 participants (who did not take part in the experiment) who rated these properties on a 7-point scale. The groups were matched for number of senses across levels of consistency, and the groups of inconsistent words were matched for position of inconsistency and consistency ratio (a measure of inconsistency defined by Rastle \& Coltheart, 1999). ${ }^{3}$ The groups were matched for lexical neighborhood across levels of senses, although the inconsistent words had fewer neighbors than did the consistent words.

Procedure. Participants viewed computer screens while wearing Beyerdynamic DT290 headset microphones. They were instructed to read aloud the words as quickly as possible without making mistakes. The microphone was connected to a SoundBlaster Live! sound card that recorded responses directly to the voice key. Onset latency was measured by triggering a timer when the sound volume to the microphone exceeded a threshold, which was set to trigger reliably for speech, but not nonspeech sounds. Stimuli were presented using the DMDX stimulus presentation program (Forster $\&$ Forster, 2003). Words were presented for $100 \mathrm{msec}$, with a 2,500msec interstimulus interval. ${ }^{4}$ If participants did not respond within 2,000 msec, a "no response" message appeared on the screen. All responses were recorded as individual sound files. The practice session consisted of 20 items. The experiment was divided into four short blocks, which began with five items not included in the analysis. Participants saw the items in different random orders.

\section{Results}

All sound files were checked; mispronunciations and occasions where the voice key was triggered by a noise other than the word onset were excluded from the latency analyses. All 22 participants were included in the error 
Table 1

Descriptive Statistics for Experiment 1

\begin{tabular}{|c|c|c|c|c|c|c|c|c|}
\hline Consistency & Senses & Example & $n$ & Senses & Letters & Phonemes & $\begin{array}{l}\text { Frequency } \\
\text { (Per } \\
\text { Million) }\end{array}$ & $\begin{array}{c}\text { Frequency } \\
\text { (Log } \\
\text { Transformed) }\end{array}$ \\
\hline \multirow[t]{2}{*}{ Inconsistent } & Many & sweat & 33 & 10.1 & 4.5 & 3.4 & 72 & 3.4 \\
\hline & Few & suite & 33 & 2.8 & 4.5 & 3.4 & 65 & 3.1 \\
\hline \multirow[t]{2}{*}{ Consistent } & Many & sweep & 33 & 10.3 & 4.4 & 3.5 & 50 & 3.3 \\
\hline & Few & swoop & 33 & 3.0 & 4.4 & 3.5 & 48 & 3.2 \\
\hline Consistency & Senses & Concreteness & Fam & niliarity & $\begin{array}{c}\text { Age of } \\
\text { Acquisition }\end{array}$ & Neighbors & Consistency & $\begin{array}{c}\text { Position of } \\
\text { Inconsistency }\end{array}$ \\
\hline \multirow[t]{2}{*}{ Inconsistent } & Many & 4.6 & & 4.4 & 2.9 & 6.1 & .24 & 2.3 \\
\hline & Few & 4.6 & & 4.4 & 3.1 & 6.1 & .29 & 2.2 \\
\hline \multirow[t]{2}{*}{ Consistent } & Many & 4.3 & & 4.4 & 2.9 & 8.6 & .83 & \\
\hline & Few & 4.5 & & 4.4 & 3.0 & 8.8 & .78 & \\
\hline
\end{tabular}

analysis, but the latency data from 1 participant were removed because of voice key trigger errors on approximately half the trials. One response over $1,000 \mathrm{msec}$ was also removed. In total, $8.5 \%$ of the data were excluded $(0.3 \%$ "no response" trials, $3.8 \%$ incorrect responses, $4.4 \%$ voice key trigger errors). For the error analyses, responses were classified as errors if the response was incorrect or absent. Most errors were regularization errors, although there were some visual errors (e.g., pronouncing bind as blind).

Mean response times and error rates were calculated separately across participants and items (see Figure 1 and Table 2 for item means) and subjected to repeated measures analyses of variance (ANOVAs) with ambiguity and consistency as factors. The response times and error rates show the predicted pattern: no ambiguity effect for the consistent words, but a sense benefit for the inconsistent words. In the response time analysis, the 17msec effect of consistency was significant $\left[F_{1}(1,20)=\right.$ $\left.25.5, p<.001 ; F_{2}(1,32)=14.0, p<.001\right]$, but there was no significant effect of ambiguity $\left[F_{1}(1,20)=1.1, p=\right.$ $\left..3 ; F_{2}(1,32)=1.0, p=.3\right)$. The predicted interaction between these variables was marginal in the subjects analysis $\left[F_{1}(1,20)=3.6, p=.07\right]$ and approached significance in the items analysis $\left[F_{2}(1,32)=2.1, p=.16\right]$. In the error analysis, the effect of consistency was significant $\left[F_{1}(1,21)=33.0, p<.001 ; F_{2}(1,32)=8.5, p<.01\right]$. The effect of ambiguity was significant in the subjects analysis and marginal in the items analysis $\left[F_{1}(1,21)=\right.$ $10.7, p<.01 ; F_{2}(1,32)=3.3, p=.08$ ]. Likewise the interaction between these variables was significant in the subjects analysis $\left[F_{1}(1,21)=6.7, p<.05\right]$ and marginal in the items analysis $\left[F_{2}(1,32)=2.8, p=.1\right]$.

\section{Discussion}

This experiment showed the predicted pattern of results: There was no ambiguity effect for the consistent words, but the inconsistent words showed a sense benefit. However, this interaction was significant only in the subjects analysis for the error rates. Note that Raaijmakers, Schrijnemakers, and Gremmen (1999) have suggested that items analyses are inappropriate for wellcontrolled stimuli such as these. On this criterion, the predicted interaction between consistency and ambiguity is significant in the error data. However, the effect is clearly small and not robust across items. The small effect size is probably a consequence of using mixed-frequency words. Strain et al. (1995) showed that the imageability effect for inconsistent words was present only for the low-frequency words. Similarly, Lichacz et al. (1999) re-

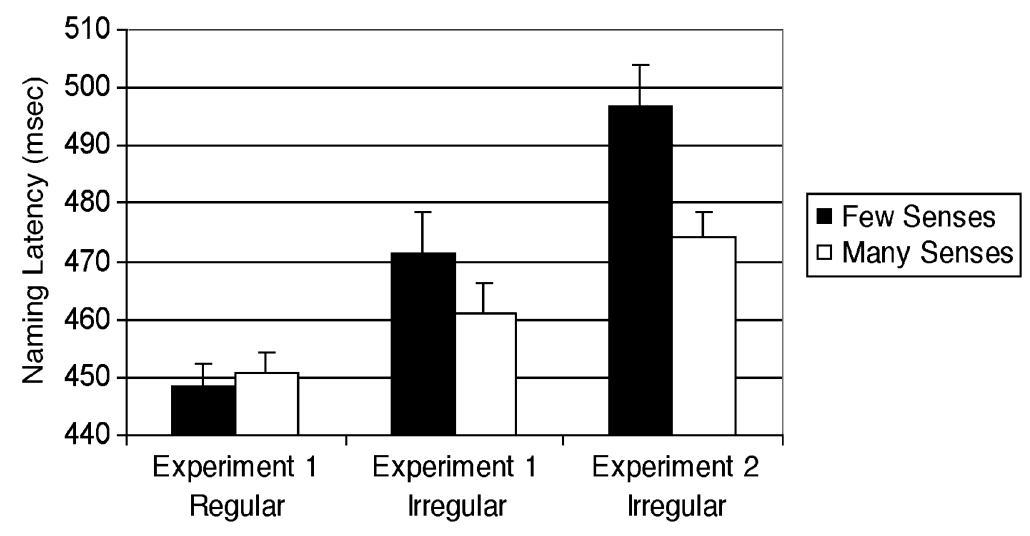

Figure 1. Experiments 1 and 2: Naming latencies. 
Table 2

Experiments 1 and 2: Percent Error

\begin{tabular}{lcccc}
\hline & \multicolumn{2}{c}{ Experiment 1 } & & Experiment 2 \\
\cline { 2 - 3 } & Consistent & Inconsistent & & Inconsistent \\
\hline Few senses & 2.1 & 7.9 & 7.5 \\
Many senses & 1.7 & 3.5 & 4.4 \\
\hline
\end{tabular}

ported an ambiguity effect that was significant for only low-frequency words. The high-frequency words in this experiment probably diluted the effect. Because the stimulus groups were matched in sets for the initial consonant cluster, it is impossible to separate these stimuli into low- and high-frequency words while maintaining onset matching. Therefore, instead of introducing a frequency manipulation, Experiment 2 attempts to increase the word sense effect within this group of well-matched mixedfrequency words.

\section{EXPERIMENT 2 Word Naming for Inconsistent Words Only}

The skilled readers in Experiment 1 read the words quickly, and there may have been insufficient time for semantics to play a role. This idea that semantic effects are relatively slow to emerge forms a key part of Strain et al.'s (1995) explanation of their imageability $\times$ consistency interaction. They argued that semantic representations are automatically accessed for all words, but that only for lowfrequency inconsistent words is the direct, nonsemantic route sufficiently slow to allow the impact of semantic representations. This account predicts that increasing reading times may increase the role of semantics.

The simplest way to increase reading times for the inconsistent words from Experiment 1 (without changing the stimuli or using explicit strategies) is to remove the consistent words. There is considerable evidence (e.g., Lupker, Brown, \& Colombo, 1997) that difficult items (e.g., inconsistent words) are named more quickly when they are mixed together with easier items (e.g., consistent words) than when they are in a pure block. Lupker et al. suggested that readers establish a flexible deadline by which articulation should start. This deadline is influenced by the overall difficulty of the stimuli and remains relatively constant over a block of trials. If this hypothesis is correct, then when the faster consistent words are removed, responses for the more difficult inconsistent words will be slower, and the ambiguity effect will increase.

\section{Method}

The participants were 15 different volunteers from the same population as those from Experiment 1. The stimuli were the two groups of inconsistent words from Experiment 1. The procedure was unchanged, except there were only two experimental blocks.

\section{Results}

Data were excluded using the criterion from Experiment 1 . In total, $16.1 \%$ of the data were excluded $(0.2 \%$ "no response" trials, $6.2 \%$ incorrect responses, $9.7 \%$ voice key trigger errors). Mean values were calculated across participants and items for response times and error rates (Figure 1 and Table 2). A paired-sample $t$ test revealed significantly faster responses for ambiguous words $\left[t_{1}(14)=4.4, p<.001 ; t_{2}(32)=2.5, p<.05\right]$. To confirm that this ambiguity effect was not due to the small difference in the frequencies of the two groups of words, an additional analysis was performed in which log-transformed frequency was entered as a covariate. This analysis showed a significant ambiguity advantage $[F(1,63)=6.2, p<.05]$ and a significant effect of frequency $[F(1,63)=19.8, p<.001]$. In the error rates, this ambiguity effect was significant in the subjects analysis, but not in the items analysis $\left[t_{1}(14)=2.2, p<\right.$ $\left..05 ; t_{2}(32)=1.3, p=.2\right]$.

These data were combined with the data for the inconsistent words from Experiment 1 in ANOVAs with experiment and ambiguity as factors. For the naming latencies, the main effect of experiment was significant only in the items analysis $\left[F_{1}(1,34)=1.4, p>.2 ; F_{2}(1,32)=\right.$ $26.9, p<.001]$; latencies were $19 \mathrm{msec}$ slower in Experiment 2 . It is unsurprising that this was not significant in the subjects analysis, given the variability between participants. The benefit for words with many senses was significant $\left[F_{1}(1,34)=29.7, p<.001\right.$; $\left.F_{2}(1,32)=4.2, p<.05\right]$. The interaction between these variables was also significant; the sense benefit was larger in Experiment $2\left[F_{1}(1,34)=6.1, p<.05 ; F_{2}(1,32)=\right.$ $5.0, p<.05]$. For the error rates, the effect of experiment was not significant (both $p$ s $>.4$ ). The main effect of ambiguity was significant in the subjects analysis $\left[F_{1}(1,35)=\right.$ $14.8, p<.001]$ and marginal in the items analysis $\left[F_{2}(1,32)=3.0, p=.09\right]$; the interaction was not significant (both $p \mathrm{~s}>.5$ ).

\section{GENERAL DISCUSSION}

These experiments used semantic ambiguity to investigate whether semantic representations are involved in reading aloud. This is the first study to use stimuli matched for both age of acquisition and onset consonant cluster and to investigate whether this semantic effect interacts with consistency. Experiment 1 revealed no effect of ambiguity for consistent words. This null result has been replicated using larger sets of consistent words matched for all the variables used in these experiments (Rodd, Acres, \& Warren, 2001) and is consistent with all current models of reading aloud. In contrast, in Experiment 1 there was a sense benefit for words with inconsistent spelling; this effect was relatively small; the relevant interaction was significant only in the subjects analysis of the error rates. In Experiment 2, this sense benefit for inconsistent words was significantly increased (for the same set of words) when the consistent words were removed from the experiment. This increased influence of semantics may result from the general slowing of responses caused by removing the easier consistent words $; 5$ it is generally assumed that the semantic route to reading is the slower of the possible routes (e.g., Strain et al., 
1995), and semantic effects may emerge only when reading is sufficiently slow. This account suggests that an ambiguity effect might also be seen in consistent words under slow reading conditions (e.g., for very low frequency words).

An alternative explanation for this effect is that readers strategically shifted their reliance on the different reading routes. When all words are inconsistent, the predictive validity of lexical cues increases relative to phonological cues, and readers may increasingly rely on the lexical (and semantic) route(s). The debate about whether readers can strategically control different processing routes is currently unresolved (see Borowsky, Owen, \& Masson, 2002; Lupker et al., 1997; Zevin \& Balota, 2000, for contrasting views). However, if the effect reported here reflects a strategic shift toward using a lexical/semantic route, then we would have expected faster, not slower, reading of the irregular words in Experiment 2 . Therefore, it is more likely that the increased semantic effect in Experiment 2 reflects a general effect of time course.

Finally, these data suggest that differences in consistency may provide an explanation for variation in the findings of other studies of ambiguity in reading aloud. First, it is likely that differences in consistency between ambiguous and unambiguous words may contribute, at least in part, to some of the reported ambiguity effects. For at least the Hino and Lupker (1996) stimuli, there were more than twice as many inconsistent words in the set of unambiguous words compared with the ambiguous words. Second, because these studies mix together consistent and inconsistent words, it is likely that the inconsistent words are indeed contributing to a real ambiguity effect; variation in the proportion of inconsistent words may account for the variation across experiments. Finally, these experiments show that the size of the ambiguity effect is critically influenced by the speed with which participants are responding (which in turn is influenced by the range of stimuli); some of the variation between earlier studies may result from variation in this factor.

In summary, these data show that semantic information can be used when skilled readers read words aloud, but that their use of semantic cues varies according to the properties of the words themselves (e.g., consistency) as well as according to the context provided by the other words in the experiment. These data are consistent with the single-route models of reading (Plaut et al., 1996; Seidenberg \& McClelland, 1989), which assume that the semantic route is critically involved in reading inconsistent words (for which the mapping between print and pronunciation is particularly difficult), and that the semantic route to reading is the slower of the possible routes and so its impact may increase when reading times are longer. The data may also be interpreted within dualroute models of reading (e.g., Coltheart et al., 2001), although this model makes no strong claims about the role of the semantic route. All published simulations using this model assume that reading can be achieved without using the semantic route. These new data require this model to assume that this route does significantly contribute to reading, and that the slower semantic route plays an increasingly important role when reading is slow.

\section{REFERENCES}

Borowsky, R., \& Masson, M. E. J. (1996). Semantic ambiguity effects in word identification. Journal of Experimental Psychology: Learning, Memory, \& Cognition, 22, 63-85.

Borowsky, R., Owen, W. J., \& Masson, M. E. J. (2002). Diagnostics of phonological lexical processing: Pseudohomophone naming advantages, disadvantages, and base-word frequency effects. Memory \& Cognition, 30, 969-987.

Chumbley, J. I., \& Balota, D. A. (1984). A word's meaning affects the decision in lexical decision. Memory \& Cognition, 12, 590-606.

Coltheart, M., Rastle, K., Perry, C., Ziegler, J., \& Langdon, R. (2001). DRC: A dual route cascaded model of visual word recognition and reading aloud. Psychological Review, 108, 204-256.

Cortese, M. J., \& Simpson, G. B. (2000). Regularity effects in word naming: What are they? Memory \& Cognition, 28, 1269-1276.

Ellis, A. W., \& Monaghan, J. (2002). Reply to commentary: Reply to Strain, Patterson, \& Seidenberg (2002). Journal of Experimental Psychology: Learning, Memory, \& Cognition, 28, 215-220.

Fera, P., Joordens, S., Balota, D. A., Ferraro, F. R., \& Besner, D. (1992). Ambiguity in meaning and phonology: Effects on naming. Paper presented at the 33rd Annual Meeting of the Psychonomic Society, St. Louis.

Forster, K. I., \& Forster, J. C. (2003). DMDX: A Windows display program with millisecond accuracy. Behavior Research Methods, Instruments, \& Computers, 35, 116-124

HINO, Y., \& LUPKER, S. J. (1996). Effects of polysemy in lexical decision and naming - An alternative to lexical access accounts. Journal of Experimental Psychology: Human Perception \& Performance, 2 1331-1356.

Lichacz, F. M., Herdman, C. M., Lefevre, J.-A., \& Baird, B. (1999). Polysemy effects in word naming. Canadian Journal of Experimental Psychology, 53, 189-193.

LUPKER, S. J., BROWN, P., \& Colombo, L. (1997). Strategic control in a naming task: Changing routes or changing deadlines? Journal of Experimental Psychology: Learning, Memory, \& Cognition, 23, 570590.

Lyons, J. (1977). Semantics (Vol. 2). Cambridge: Cambridge University Press.

Monaghan, J., \& Ellis, A. W. (2002). What exactly interacts with spelling-sound consistency in word naming? Journal of Experimental Psychology: Learning, Memory, \& Cognition, 28, 183-206.

PARKS, R., RAY, J., \& BLAND, S. (1998). Wordsmyth English dictionarythesaurus. University of Chicago. Retrieved February 1, 1999, from http://www.wordsmyth.net/Chicago.

Plaut, D. C., McClelland, J. L., Seidenberg, M. S., \& Patterson, K. (1996). Understanding normal and impaired word reading: Computational principles in quasi-regular domains. Psychological Review, 103, 56-115.

RaAijmakers, J. G. W., Schrijnemakers, J. M. C., \& Gremmen, F. (1999). How to deal with "the language-as-fixed-effect fallacy": Common misconceptions and alternative solutions. Journal of Memory \& Language, 41, 416-426.

Rastle, K., \& ColTHEART, M. (1999). Serial and strategic effects in reading aloud. Journal of Experimental Psychology: Human Perception \& Performance, 25, 482-503.

RASTLE, K., \& DAVIS, M. H. (2002). On the complexities of measuring naming. Journal of Experimental Psychology: Human Perception \& Performance, 28, 307-314.

RoDD, J. M., ACRES, K., \& WARREN, A. (2001). Effects of semantic ambiguity in lexical decision and word naming. Paper presented at the XII Conference of the European Society for Cognitive Psychology, Edinburgh.

Rodd, J. M., Gaskell, M. G., \& Marslen-Wilson, W. D. (2002). 
Making sense of semantic ambiguity: Semantic competition in lexical access. Journal of Memory \& Language, 46, 245-266.

Seidenberg, M. S., \& McClelland, J. L. (1989). A distributed, developmental model of word recognition and naming. Psychological Review, 96, 523-568.

SPIELER, D. H., \& BALOTA, D. A. (1997). Bringing computational models of word naming down to the item level. Psychological Science, $\mathbf{8}$, 411-416.

Strain, E., \& Herdman, C. M. (1999). Imageability effects in word naming: An individual difference analysis. Canadian Journal of Experimental Psychology, 53, 347-359.

Strain, E., Patterson, K., \& Seidenberg, M. S. (1995). Semantic effects in single-word naming. Journal of Experimental Psychology: Learning, Memory, \& Cognition, 21, 1140-1154.

Strain, E., Patterson, K., \& Seidenberg, M. S. (2002). Theories of word naming interact with spelling-sound consistency. Journal of Experimental Psychology: Learning, Memory, \& Cognition, 28, 207-214.

Zevin, J. D., \& Balota, D. A. (2000). Priming and attentional control of lexical and sublexical pathways during naming. Journal of Experimental Psychology: Learning, Memory, \& Cognition, 26, 121-135.

\section{NOTES}

1. Although this is a measure of consistency and not regularity, the two variables are highly correlated.

2. Contrasting consistency with ambiguity between unrelated meanings is difficult because (as described above) inconsistent words with multiple unrelated meanings are very rare.

3. Consistency was calculated as (number of friends - number of enemies)/(number of friends + number of enemies): -1 indicates perfect inconsistency, +1 indicates perfect consistency.

4. The fast presentation rate was intended to increase difficulty and thereby increase participants' reliance on semantic information. However, a replication of Experiment 1 in which the words remained on the screen until participants responded showed the same pattern of results, suggesting that this manipulation did not affect participants' use of semantic information.

5. Although Experiment 1 was twice as long as Experiment 2, the faster performance in Experiment 1 was not simply a practice effect. In Experiment 1, participants were significantly slower in the second half of the experiment than in the first half.

APPENDIX

Experiments 1 and 2: Response Times (RTs, in Milliseconds) and Percent Error

\begin{tabular}{|c|c|c|c|c|c|c|c|c|c|c|c|c|c|c|c|}
\hline \multicolumn{10}{|c|}{ Inconsistent } & \multicolumn{6}{|c|}{ Consistent } \\
\hline & \multicolumn{4}{|c|}{ Few Senses } & & \multicolumn{4}{|c|}{ Many Senses } & & \multirow{2}{*}{\multicolumn{2}{|c|}{$\frac{\text { Few Senses }}{\text { Exp. } 1}$}} & & \multirow{2}{*}{\multicolumn{2}{|c|}{$\frac{\text { Many Senses }}{\text { Exp. } 1}$}} \\
\hline & \multicolumn{2}{|c|}{ Exp. 1} & \multicolumn{2}{|c|}{ Exp. 2} & & \multicolumn{2}{|c|}{ Exp. 1} & \multicolumn{2}{|c|}{ Exp. 2} & & & & & & \\
\hline & RT & Error & RT & Error & & RT & Error & RT & Error & & RT & Error & & RT & Error \\
\hline bull & 465 & 0.0 & 478 & 13.3 & bind & 508 & 22.7 & 538 & 13.3 & beef & 443 & 0.0 & bounce & 457 & 4.5 \\
\hline bruise & 473 & 0.0 & 474 & 0.0 & broad & 483 & 4.5 & 471 & 13.3 & breeze & 457 & 0.0 & brand & 469 & 4.5 \\
\hline cow & 443 & 0.0 & 468 & 0.0 & comb & 486 & 9.1 & 499 & 0.0 & coal & 434 & 0.0 & kick & 446 & 4.5 \\
\hline chrome & 492 & 0.0 & 491 & 0.0 & cruise & 469 & 0.0 & 501 & 0.0 & crime & 473 & 4.5 & crust & 457 & 0.0 \\
\hline debt & 470 & 0.0 & 471 & 6.7 & dead & 487 & 9.1 & 490 & 6.7 & desk & 444 & 0.0 & damp & 448 & 0.0 \\
\hline drown & 447 & 0.0 & 485 & 0.0 & dread & 452 & 0.0 & 474 & 6.7 & drab & 449 & 4.5 & drain & 448 & 4.5 \\
\hline fierce & 488 & 0.0 & 499 & 0.0 & folk & 510 & 4.5 & 480 & 6.7 & fame & 450 & 0.0 & fake & 464 & 0.0 \\
\hline four & 484 & 0.0 & 511 & 0.0 & foot & 448 & 0.0 & 466 & 0.0 & five & 475 & 0.0 & feed & 480 & 0.0 \\
\hline friend & 489 & 4.5 & 469 & 0.0 & front & 507 & 0.0 & 455 & 0.0 & fright & 493 & 4.5 & freeze & 498 & 0.0 \\
\hline gown & 458 & 0.0 & 490 & 0.0 & ghost & 454 & 0.0 & 449 & 0.0 & gaze & 441 & 0.0 & gun & 437 & 0.0 \\
\hline gasp & 454 & 0.0 & 498 & 0.0 & guide & 466 & 0.0 & 453 & 0.0 & gift & 459 & 4.5 & gain & 455 & 0.0 \\
\hline guest & 445 & 0.0 & 452 & 0.0 & guard & 448 & 0.0 & 475 & 0.0 & gate & 444 & 4.5 & game & 425 & 4.5 \\
\hline haunt & 520 & 0.0 & 525 & 6.7 & hood & 448 & 0.0 & 483 & 0.0 & hoist & 467 & 0.0 & hike & 442 & 0.0 \\
\hline halt & 458 & 0.0 & 510 & 0.0 & hook & 437 & 0.0 & 451 & 6.7 & hint & 435 & 0.0 & heap & 452 & 0.0 \\
\hline month & 458 & 4.5 & 468 & 13.3 & mind & 421 & 0.0 & 419 & 6.7 & male & 431 & 0.0 & mess & 437 & 0.0 \\
\hline most & 461 & 18.2 & 463 & 6.7 & move & 422 & 0.0 & 450 & 0.0 & mile & 448 & 0.0 & meet & 423 & 0.0 \\
\hline pint & 476 & 18.2 & 490 & 0.0 & pearl & 464 & 0.0 & 518 & 0. & pond & 464 & 0.0 & pinch & 431 & 0.0 \\
\hline route & 439 & 0.0 & 466 & 0.0 & rhyme & 530 & 0.0 & 506 & 0.0 & robe & 445 & 0.0 & rope & 466 & 0.0 \\
\hline cite & 482 & 13.6 & 489 & 0.0 & sword & 451 & 9.1 & 480 & 0.0 & saint & 437 & 0.0 & sail & 440 & 0.0 \\
\hline soup & 431 & 0.0 & 459 & 0.0 & scent & 437 & 0.0 & 479 & 0.0 & soap & 424 & 0.0 & seed & 423 & 0.0 \\
\hline $\operatorname{sir}$ & 422 & 4.5 & 497 & 6.7 & salt & 419 & 0.0 & 437 & 0.0 & site & 443 & 0.0 & sing & 426 & 4.5 \\
\hline son & 415 & 0.0 & 457 & 0.0 & soul & 431 & 0.0 & 434 & 0.0 & six & 422 & 0.0 & safe & 427 & 0.0 \\
\hline chef & 487 & 36.4 & 568 & 53.3 & shove & 429 & 0.0 & 464 & 0.0 & sheep & 410 & 0.0 & shunt & 449 & 4.5 \\
\hline swan & 428 & 0.0 & 460 & 6.7 & swarm & 430 & 0.0 & 490 & 0.0 & swoon & 433 & 0.0 & sway & 423 & 0.0 \\
\hline suite & 470 & 36.4 & 510 & 33.3 & sweat & 409 & 9.1 & 463 & 13.3 & swoop & 415 & 0.0 & sweep & 425 & 0.0 \\
\hline threat & 466 & 0.0 & 530 & 0.0 & thread & 476 & 0.0 & 507 & 6.7 & thrive & 480 & 13.6 & thrust & 477 & 0.0 \\
\hline thyme & 632 & 36.4 & 604 & 13.3 & tease & 468 & 0.0 & 433 & 0.0 & tale & 420 & 0.0 & tame & 437 & 0.0 \\
\hline tomb & 460 & 4.5 & 463 & 6.7 & ton & 450 & 0.0 & 462 & 0.0 & tent & 435 & 0.0 & tilt & 498 & 0.0 \\
\hline trough & 563 & 13.6 & 641 & 46.7 & tread & 464 & 9.1 & 468 & 20.0 & trance & 437 & 4.5 & tramp & 477 & 0.0 \\
\hline veil & 498 & 9.1 & 516 & 0.0 & vow & 511 & 0.0 & 518 & 20.0 & vine & 512 & 4.5 & void & 485 & 0.0 \\
\hline wart & 497 & 31.8 & 528 & 33.3 & wad & 498 & 18.2 & 493 & 13.3 & wick & 464 & 0.0 & wade & 454 & 4.5 \\
\hline wasp & 437 & 0.0 & 451 & 0.0 & wolf & 453 & 0.0 & 472 & 0.0 & wig & 435 & 0.0 & wink & 437 & 4.5 \\
\hline womb & 454 & 0.0 & 510 & 0.0 & worm & 444 & 9.1 & 466 & 13.3 & wage & 476 & 0.0 & wail & 459 & 0.0 \\
\hline
\end{tabular}

